\title{
Trade and invasive species risk mitigation: Reconciling WTO compliance with maximising the gains from trade ${ }^{\text {ts }}$
}

\author{
David C. Cook ${ }^{\mathrm{a}, \mathrm{b}, *}$, Rob W. Fraser ${ }^{\mathrm{c}, \mathrm{d}, 1}$ \\ ${ }^{\text {a }}$ CSIRO Entomology, GPO Box 1700, Canberra 2601, ACT, Australia \\ ${ }^{\mathrm{b}}$ Fenner School of Environment and Society, The Australian National University, Australia \\ ${ }^{\mathrm{c}}$ Kent Business School, Imperial College Wye Campus, Wye, Ashford, Kent TN25 5AH, United Kingdom \\ ${ }^{\mathrm{d}}$ Agricultural and Resource Economics, The University of Western Australia, Australia
}

Received 31 January 2007; received in revised form 29 May 2007; accepted 10 July 2007

\begin{abstract}
This paper analyses the issue of balancing the gains from trade with the risk of pest and disease transference. Two decision frameworks for determining whether or not to permit trade in a potentially invasive species-carrying good are presented. The first considers only the potential production losses resulting from an invasive species entering through a trade pathway, as is prescribed by WTO compliance. The second is a unilateral welfare-maximising approach which considers the consumer gains from trade, the loss of domestic producers' market share and expected damage from the invasive species. It is shown that these alternative decision frameworks can be reconciled such that they produce the same outcome regarding whether or not trade is to be permitted. The key parameters which influence these decisions are also highlighted.
\end{abstract}

(C) 2007 Elsevier Ltd. All rights reserved.

Keywords: Biosecurity; Import risk analysis; Invasive species

\section{Introduction}

The role of economists in invasive species risk management strategies and trade is not yet clear, particularly in relation to risks to plant health. An invasive species is one that if introduced will become established and inflict damage on the economy, natural environment and/or society. ${ }^{2}$

\footnotetext{
We are grateful to two anonymous reviewers for their helpful comments on a previous version of this paper.

* Corresponding author. Address: CSIRO Entomology, GPO Box 1700, Canberra 2601, ACT, Australia. Tel.: +61 26246 4093; fax: +61 26246 4000 .

E-mail addresses: david.c.cook@csiro.au (D.C. Cook), r.fraser@ imperial.ac.uk (R.W. Fraser).

${ }^{1}$ Tel.: +4402075942698.

2 The terms 'invasive species', 'exotic pests' and 'pests and diseases' are used interchangeably. In all instances it is to be assumed we refer to species that are capable of inflicting economic, environmental and/or socioeconomic damage to a country or region if they gain entry and become established. This paper concerns invasive species whose primary hosts are plants.
}

Before establishment takes place, a means of arriving in a new area is needed, and it is here that trade in plant (and animal) products is seen to play a role. The significance of that role is a matter for debate. Some studies assert a definite correlation between trade volume and the number of invasive species incursions (e.g. Levine and D'Antonio (2003)), while others find no evidence of a definite relationship (e.g. Lonsdale et al. (2001)). Assuming there to be some positive relationship between trade volume and incursions, it would seem a relatively straightforward matter for a trading nation to use economic models to weigh up the benefits of trade with the increased risk of invasive species damage. However, the World Trade Organisation (WTO) does not require this of its Member nations when imposing quarantine measures. Article 5 of the Agreement on the Application of Sanitary and Phytosanitary Measures (SPS Agreement), which outlines relevant economic factors to be taken into account in assessing risk mitigation measures, only considers production risks to be relevant (GATT, 1994). Completely absent from the Article 5 is one of the 
fundamental drivers for trade, that of consumer benefit (Roberts, 1998).

This paper looks at the information potentially provided by economic advisors on trade issues in two different decision contexts. The first instance takes into consideration the rules and obligations governing Members of the WTO in international trade. Under current WTO guidelines the decision of whether to import a potentially contaminated product depends on whether the perceived risk exceeds an acceptable standard known as the appropriate level of protection (ALOP). The second situation assumes that instead of a WTO-compliance objective, there is a regulatory authority intent on maximising social-welfare in the home economy. In this case a social welfare assessment would be undertaken which calculates the net effect of trade from resultant changes in producer and consumer surplus. ${ }^{3}$ Producer losses would stem from two sources: lower product prices induced by international competition and expected damage losses resulting from exotic pest and disease incursions (Roberts, 2001). Consumer gains would take the form of an increased volume available for consumption at cheaper prices as long as the landed price of imported product is below a closed economy price. The aim of this paper is to show that these decision frameworks regarding whether or not to permit trade in a potentially invasive species-carrying good may in fact be complementary, and can be reconciled such that they produce the same outcome regarding permission to trade.

The paper is structured as follows. Section "Background" provides a background to the economics of quarantine risk evaluation, presented largely from an Australian perspective. Section "Alternative decision frameworks" outlines the elements of an economic decision framework in the two contexts outlined above and shows how these alternative decision frameworks can be reconciled, as well as highlighting the key parameters in deciding whether or not to permit trade. Section "Complexities" discusses some of the unresolved complexities before Section "Conclusions" draws conclusions.

\section{Background}

In its current form, the SPS Agreement stipulates that any welfare effects resulting from trade in potentially contaminated goods be measured in terms of producer welfare. Paragraph 3, Article 5 of the SPS Agreement (GATT, 1994) states:

In assessing the risk to animal or plant life or health and determining the measure to be applied for achieving the

\footnotetext{
${ }^{3}$ Producer surplus is defined as net revenue earned by a producer from the sale of a good at a price above the minimum acceptable price they would have been willing to sell for before having to leave the market. Consumer surplus is the financial equivalent of the extra utility gained by consumers from purchasing a good at a price lower than what they were willing to pay for it.
}

appropriate level of sanitary or phytosanitary protection from such risk, Members shall take into account as relevant economic factors: the potential damage in terms of loss of production or sales in the event of the entry, establishment or spread of a pest or disease; the costs of control or eradication in the territory of the importing Member; and the relative cost-effectiveness of alternative approaches to limiting risks.

Article 5 also specifies that any restrictions placed on imported goods to reduce expected producer losses be justifiable by way of a risk analysis, and that the methodology used for this analysis draw upon internationally recognised methodologies.

As a WTO Member country, Australia can impose restrictions on an imported commodity and remain WTO-compliant if it carries out an import risk analysis (IRA) that demonstrates that the contamination risk to domestic industries being protected against is sufficiently high to warrant the SPS measures imposed. It can only restrict trade up to the point where the risk posed is 'acceptable'. Australian IRAs are the responsibility of Biosecurity Australia, and an acceptable risk is one that does not exceed the country's ALOP. The ALOP is a locus of arrival probabilities and incursion impacts with a unique product representing the maximum tolerable level of risk associated with imports before a refusal is made to a market entry request (Cook, 2002). It is worth noting that for a number of reasons no country has to date articulated its ALOP (Henson, 2001; Cook and Fraser, 2002).

The semi-quantitative IRA method used by Biosecurity Australia to determine the risk associated with imported products has recently been drawn into question. In 2004 it was revealed errors in the IRA process for Philippine bananas (Biosecurity Australia, 2002) caused an underestimate of the potential risks associated with Moko Disease entering Australia by a factor of three (Biosecurity Australia, 2004c). Less than six months later a Federal Court ruled that another IRA concerning the import of pork (Biosecurity Australia, 2004a) also contained errors relating to a disease threat, and that the subsequent allowance of pork imports from the US (subject to SPS measures) was based on unreasonable assessment (Australian Pork Ltd v Director of Animal \& Plant Quarantine, 2005). ${ }^{4}$ These incidents, coupled with several long standing issues relating to the time taken to complete IRAs and communication with the States and Territories in relation to area freedoms, have influenced the Department of Agriculture, Fisheries and Forestry (DAFF) to establish the Australian Centre of Excellence for Risk Analysis in March 2006. ${ }^{5}$

\footnotetext{
${ }^{4}$ The judge in this case was critical of the IRA methodology used, particularly in relation to Post-weaning Multisystemic Wasting Syndrome.

${ }^{5}$ Although Nairn et al. (1996) called for the formation of a centre for quarantine-related risk analysis, this recommendation was not acted upon in the initial governmental response to the review (Tanner and Nunn, 1998).
} 
The economic component of Australian IRAs completed in the last twenty years has differed significantly. Typically, economic analyses of market access for imported products have tended to follow persistent requests from high-profile sources, focussing on specific quarantine decisions as opposed to the broader social welfare implications of policy options (Nunn, 2001; Roberts, 2001). The way in which the economic implications of imports have been estimated appears to have been done on a case by case basis, rather than using a standardised method. This is true of both pre- and post-SPS Agreement analyses. Case studies have used a variety of economic analyses, including those that simply assume an outbreak scenario only affecting producers, those that seek to put a probability on this occurrence, those considering both consumer and producer impacts, or combinations of these.

Hinchy and Low (1990) addressed a New Zealand request made in 1989 to import apples into Australia, where the major disease transference concern was (and remains) fireblight. ${ }^{6}$ Australia's detailed response to this request, coordinated by the Australian Quarantine and Inspection Service (AQIS), was in line with the recommendations of the so-called 'Lindsay Review' of Australian quarantine in 1988 (DPIE, 1988). The economic component provided by Hinchy and Low (1990) was accompanied by a biological component (Roberts, 1991). ${ }^{7}$ The former took the form of a benefit cost analysis comparing the expected consumer and producer surplus changes resulting from relaxing quarantine laws protecting the apple industry. In 1995 New Zealand made another request to access the Australian apple market. This time the economic analysis came in the form of Bhati and Rees (1996), which was quite different in approach to that of Hinchy and Low (1990). Expected consumer surplus change is not discussed. The analysis only considers possible producer surplus losses to pome fruit growers if a fireblight outbreak were to occur. ${ }^{8}$ Both import access requests were denied. Viljoen et al. (1997) presents evidence that the import ban was indeed justified given that the pear industry in Australia could collapse in the event of a fireblight outbreak.

A market access application concerning salmon products, again from New Zealand, was at the centre of an eco-

\footnotetext{
${ }^{6}$ Fireblight is a disease caused by the bacteria Erwinia amylovora that affects plants from the family Rosaceae, including apples and pears. Once established the bacteria can not be eliminated from an orchard, but costly measures such as an aggressive pruning regime can be taken to limit the extent of infection (Buckner, 1995). The disease originated in the United States, but has spread to most apple growing areas of the world with the exception of Australia. It was first discovered in New Zealand in 1919, and apples have been refused entry to Australia since 1921 (Biosecurity Australia, 2004b).

${ }^{7} \mathrm{~A}$ theoretical discussion of the techniques used in this analysis appears in Hinchy and Fisher (1991).

${ }^{8}$ Like Hinchy and Low (1990) and Bhati and Rees (1996) base their assumptions about the impact of the fireblight disease on the information contained in Roberts (1991).
}

nomic analysis conducted in 1991. Salmon meat potentially provides an entry pathway for Whirling Disease. ${ }^{9}$ The AQIS response, McKelvie (1991), provides a scenario analysis and derives possible damage estimates from the introduction of whirling disease to three fisheries. Neither the likelihood of disease arrival, the effect on domestic salmon consumers, nor the likelihood of scenario occurrence is discussed. Following another request to access Australia's salmon market in 1994, this time from Canada (which had been trying to gain access to this market since the mid1970s), a similar economic analysis was prepared in McKelvie et al. (1994). This analysis dealt with two salmon diseases considered an importation risk, Furunculosis and Infectious Haematopoietic Necrosis (IHN). ${ }^{10}$ Again, the analysis comprises of a gross estimate of producer surplus loss in the event of a disease incursion, rather than a net welfare assessment. Once again, both of these requests were denied. This prompted Canada to take the matter to the WTO Dispute Settlement Body (DSB). In June 1998, the Panel released its report which found Australia's market access restrictions to be inconsistent with the WTO Agreement on the SPS Agreement, and recommended that the DSB request Australia to bring its measures in to line with its obligations under the SPS Agreement (WTO, 2000). This ruling was unsuccessfully appealed by the Australian Government. Further discussions between the two countries failed to find a mutually acceptable solution, freeing the way for Canada to take retaliatory actions against goods imported from Australia.

Another trade issue which prompted an economic analysis concerned the importation of chicken meat from countries such as the United States, Denmark, Thailand and New Zealand. The economic implications of imports from these countries were examined in Hafi et al. (1994), which used the example of Newcastle disease ${ }^{11}$ to illustrate the economic implications of relaxing quarantine protocols

\footnotetext{
${ }^{9}$ If left untreated Whirling Disease causes exhaustion, malnutrition and deformities in salmonids. Experience with the disease in Europe and the United States demonstrates that it is possible to manage its impact effectively by rearing fish in isolated, disease-free tanks before transferring them to 'grow-out' facilities and (potentially) diseased waters (McKelvie, 1991). Although effective, this is an expensive process.

${ }^{10}$ Furunculosis is a bacterial infection that affects most salmonid species (with the exception of Atlantic salmon) causing lesions that render fish unmarketable. It is common in Canada, North America, the British Isles, Europe and Japan, and is easily transmitted by contact with contaminated water, equipment and infected fish (McKelvie et al., 1994).

${ }^{11}$ Newcastle disease is caused by a virus known as avian paramyxovirus, and affects domestic fowls, turkeys, pheasants, pigeons, quail, guinea fowl and many species of wild and captive birds. Symptoms of the disease are highly varied, but generally include loss of appetite, a decline in egg production, diarrhoea and a severe cough, and are usually followed by head tremors and wing paralysis, and eventual death. The disease is easily spread through contact with diseased birds, carcasses and offal, and mortality rates can be between 10 and 100 percent in affected flocks in a very short space of time (24-72 h) (Hafi et al., 1994). A vaccination is available for the disease, which would add to the variable cost of production, but eradication is the current policy stance under the Australian Veterinary Emergency Plan (AUSVETPLAN) (DPIE, 1990).
} 
and allowing conditional access to the Australian chicken meat market. The method used in this analysis is similar to that of Hinchy and Low (1990) in that a critical probability of disease arrival is determined which brings the benefits and probable costs of trade into balance. Trade benefits were calculated as the change in consumer surplus resulting from lower domestic prices for chicken products, while the costs calculations were based on a severe Newcastle disease outbreak scenario causing a contraction in domestic supply of close to 20 percent.

James and Anderson (1998) present an analysis of Australia's ban on international banana imports based on a true social welfare analysis. Consumer surplus losses resulting from import protection are compared to a hypothetical producer surplus loss induced by a relaxing of trade restrictions. Here, the consumer gains are shown to outweigh production losses, casting doubt over the validity of the ban in terms of net social welfare. Gains from the trade ban are more than likely outweighed by the cost to consumers. The SPS Agreement is ignored in the sense that consumer gains are considered just as important as producer losses, and recognition is also given to the fact that a closed economy imposes costs. Social welfare is therefore skewed in favour of producers at the starting point of the analysis.

\section{Alternative decision frameworks}

Assume initially, that in the absence of existing trade, Australia is confronted with the choice of whether or not to import a homogenous good from another country. This good has the potential to act as a pathway for a harmful host-specific pest or disease that the source country has but Australia does not. Further assume that in the absence of price-inflating SPS measures, the landed price of imported product $\left(p^{* *}\right)$ is below that of a domestic equivalent $\left(p_{0}\right)$, and that the domestic market is small relative to the rest of the world in terms of its influence on the world price. The domestic market for the product is characterised by a downward sloping demand curve, $f(q)$, and an upward sloping supply curve, $g(q)$. This is situation and is depicted in Fig. 1, the details of which are explained below.

What factors should Australian trade regulators consider if they are social welfare maximisers? Well that depends. Two different evaluations of trade policy with respect to this "risky" import are considered below.

\section{WTO compliance}

If, as a WTO Member, Australia decides it is going to honour its obligations and strictly abide by the SPS Agreement it need only consider the potential effects of trade on its producers in terms of the threat posed by the pest or disease. It would then act to minimise potential welfare loss with import restrictions or entry requirements.

Formally, the domestic losses that could result from an exotic pest or disease outbreak resulting from contami-

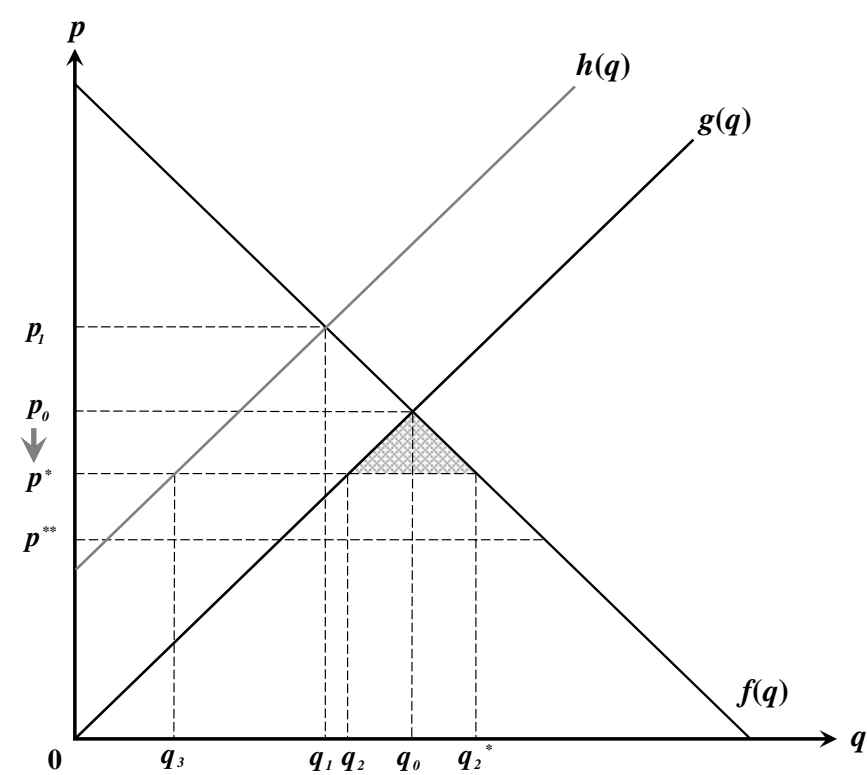

Fig. 1. The quarantine-restricted trade decision from a closed economy position.

nated imports can be estimated as the total expected change in producer surplus brought about by an incursion-induced (negative) supply shock, plus the cost of controlling the species (be it eradication or suppression). The probability of arrival $(r)$ is most likely an increasing function of the quantity of imported product, $q^{*}$, and a decreasing function of the pre-border and border SPS measures the good is subjected to in the process of importation with cost $t$ (i.e. $r\left(q^{*}, t\right)$ ). To simplify the effects of uncertainty, it is useful to assume a deterministic change in the probability of arrival with SPS compliant imports from abroad $\left(r^{*}\right)$ relative to the probability of arrival without imports $(r)$ (i.e. $r^{*}>r$.

As a starting point, a closed economy involves domestic producers with a supply schedule $g(q)$ providing the total supply $\left(q_{0}\right)$ to the domestic market at a price $p_{0}$. If an incursion were to occur (despite there being no trade pathway) the supply curve will shift inwards to $h(q)$, and the new equilibrium price will rise to $p_{1}$ at which $q_{1}$ will be demanded. Note that even when no trade takes place $0<r<1$.

If the market were to move from a closed to a quarantine-restricted trade situation the prevailing market price will fall to the world price $\left(p^{* *}\right)$ plus $t$ (i.e. $p^{*}=p^{* *}+t$ where $t$ is sufficiently low to ensure that $\left.p_{0}>p^{*}\right)$. Domestic producers will remain suppliers to the domestic market as long as $p^{*}$ remains above the minimum average variable cost of production, supplying a lower quantity $q_{2}$. However, if trade takes place the likelihood of contaminated product reaching Australia via the trade pathway provided by $q_{2}^{*}-q_{2}$ imports increases from $r$ to $r^{*}$. In the event that a pest or disease incursion does result the supply curve will shift inwards to $h(q)$, further reducing the quantity supplied by domestic producers to $q_{3}$. 
Following an incursion, a coordinated control campaign is mounted against the invasive species to either eradicate it or restrict its abundance and distribution. Assume the total cost of control will depend only on the size of the outbreak upon detection $(s)$ and the total reduction in abundance and distribution sought by the campaign $(a)$, and is denoted $c(s, a)$ (Olson and Roy, 2005). Total control costs are assumed to be increasing in both $a$ and $s$, while marginal control costs are increasing in $a$ and non-increasing in $s$.

Faced with the prospect of biological contamination, biosecurity regulators in Australia need to decide if the risks associated with this particular organism are sufficiently low to justify importation. Their decision rule relies on the following information. Firstly, it relies on the Expected Impact of the invasive species if no trade takes place $\left(\mathrm{EI}_{A}\right)$ :

$$
\begin{aligned}
\mathrm{EI}_{A}= & r \cdot\left[\left(p_{0}-\int_{0}^{q_{0}} g(q)\right) \cdot \mathrm{d} q-\left(p_{1}-\int_{0}^{q_{1}} h(q)\right) \cdot \mathrm{d} q\right] \\
& +r \cdot c(s, a)
\end{aligned}
$$

Eq. (1) states that $\mathrm{EI}_{A}$ is equal to the expected difference between the producer surplus under autarky if no outbreak occurs and the producer surplus under autarky if an outbreak occurs, plus the expected cost of control.

Secondly, the regulator needs to know the expected impact of the invasive species if trade takes place $\left(\mathrm{EI}_{Q}\right)$ :

$$
\begin{aligned}
\mathrm{EI}_{Q}= & r^{*} \cdot\left[\left(p^{*}-\int_{0}^{q_{2}} g(q)\right) \cdot \mathrm{d} q-\left(p^{*}-\int_{0}^{q_{3}} h(q)\right) \cdot \mathrm{d} q\right] \\
& +r^{*} \cdot c(s, a)
\end{aligned}
$$

Eq. (2) states that $\mathrm{EI}_{Q}$ is the expected difference between the producer surplus with trade if SPS measures are 100 percent effective and the producer surplus if an outbreak occurs, plus the expected cost of control.

The final piece of information required is a maximum standard level of expected impact, or ALOP. The decision of whether or not trade should be permitted is either:

(a) If $\left(\mathrm{EI}_{Q}-\mathrm{EI}_{A}\right)-\mathrm{ALOP}<0$, allow trade to occur, or

(b) If $\left(\mathrm{EI}_{Q}-\mathrm{EI}_{A}\right)-\mathrm{ALOP}>0$, do not allow trade to occur.

\section{Unilateral welfare maximisation}

The obvious omissions in the previous assessment are consumer surplus changes. The importation of potentially contaminated goods brings with it consumer gains from trade with a lowering of prices. Imports provide a greater quantity of the good to consumers at a lower price, $p^{*}$. It follows that a closed economy (or autarky) situation imposes costs to consumers and gains to domestic produc- ers. The decision of whether to import a commodity subject to SPS measures must be made relative to a closed economy situation to establish the consumer benefits achieved by permitting trade.

Consider the effects on all consumers and producers of moving from a closed economy to a quarantine-restricted trade situation. The prevailing market price would be expected to fall to $p^{*}$ at which domestic producers are willing to supply $q_{2}$ of the total quantity demanded, $q_{2}^{*}$. The total consumer surplus gained by allowing quarantinerestricted trade is given by

$$
\Delta \mathrm{CS}=\left(\int_{0}^{q_{2}^{*}} f(q)-p^{*}\right) \cdot \mathrm{d} q-\left(\int_{0}^{q_{0}} f(q)-p_{0}\right) \cdot \mathrm{d} q
$$

This change in consumer surplus is the difference between the post-quarantine trade consumer surplus and autarkic consumer surplus. This gain comes at the cost of competition-induced producer surplus losses to domestic producers:

$$
\Delta \mathrm{PS}=\left(p_{0}-\int_{0}^{q_{0}} g(q)\right) \cdot \mathrm{d} q-\left(p^{*}-\int_{0}^{q_{2}} g(q)\right) \cdot \mathrm{d} q
$$

This producer surplus change is calculated as the difference between the autarkic producer surplus and post-trade producer surplus. The resultant net gains, termed traditional gains from trade in Snape and Orden (2001), are simply the difference between consumer surplus gain and producer surplus loss ignoring the possibility of an invasive species incursion. That is, the traditional gains from trade here represent the change in producer and consumer surplus as a result of price differentials between the domestic equilibrium and landed price of imports:

$\mathrm{GT}=\Delta \mathrm{CS}-\Delta \mathrm{PS}$

This is represented as the shaded region in Fig. 1. These traditional trade effects do not take the increase in invasive species risk (EI*) brought about by trade in to account, which from Section "WTO compliance" is given by

$\mathrm{EI}^{*}=\mathrm{EI}_{Q}-\mathrm{EI}_{A}$

The total gains to consumers resulting from trade must be sufficiently high to offset the expected losses to domestic producers for there to be a net gain from moving from a closed economy to a quarantine-restricted trade setting. Combining the changes in consumer and producer surplus with the expected impact of an invasion on producers, the expected net gains from trade $\left(\mathrm{NG}_{\mathrm{E}}\right)$ can be stated as

$\mathrm{NG}_{\mathrm{E}}=\mathrm{GT}-\mathrm{EI}^{*}$

It follows that the decision of whether or not to import the potentially contaminated product is either:

(a) If $\mathrm{GT}-\mathrm{EI}^{*}>0$, allow trade to occur, or

(b) If $\mathrm{GT}-\mathrm{EI}^{*}<0$, do not allow trade to occur. 


\section{Reconciliation}

The exclusion of consumer interests in the decision of a WTO-compliant Australia to allow trade in a particular commodity does not necessarily lead to socially undesirable trade policies. All depends on the size of the ALOP in relation to GT. By using GT as a basis for the ALOP, the welfare of consumers can be embedded in the decision-making process despite the producer loss minimisation being the main motivation for policy makers.

To see this, consider a trade decision involving a move from a closed economy to a quarantine-restricted trade in a particular commodity. Now assume that a regulatory authority setting the ALOP by which imported goods are assessed uses GT as a measure of what the standard should be:

$\mathrm{GT}=\mathrm{ALOP}=\Delta \mathrm{CS}-\Delta \mathrm{PS}$

By setting the ALOP at the same level as GT and comparing it to an expected impact assessment (e.g. EI*), the WTO-compliant regulatory authority would give exactly the same policy advice as a unilateral welfare maximising-economist. Both are determining if $\mathrm{NG}_{\mathrm{E}}>0$ such that $\mathrm{EI}^{*}<\mathrm{GT}$, so the decision on whether or not to allow quarantine-restricted trade to take place or not produces the same outcome for both decision frameworks. However, if the ALOP is set below GT then the WTO-compliance decision rule will restrict trade more than the unilateral welfare maximisation rule (and vice versa).

In addition to the standard roles of the magnitudes of the elasticities of demand and supply, one of the key drivers of Eq. (7) is the magnitude of the difference between the probabilities of arrival in a quarantine-restricted trade setting and in a closed economy (i.e. $r^{*}-r$ ). This is determined by the effectiveness of the quarantine-restriction measures and has a positive impact on EI*. For example, if quarantine-restriction measures are relatively effective, then $r^{*}-r$ will be small and $\mathrm{EI}^{*}$ will be small, thereby encouraging quarantine-restricted trade.

The cost of the quarantine-restriction measures $(t)$ is also crucial in Eq. (7) given its role in determining GT (although it affects $\mathrm{EI}^{*}$ as well). If it is the case that quarantine restrictions are relatively cheap (i.e. $t$ is small), then GT will be relatively large and SPS-restricted trade will tend to be preferred.

It follows that, compared with the standard gains-fromtrade type of analysis, quarantine-restricted trade is most likely to be welfare-maximising in situations where both $t$ and $r^{*}-r$ are relatively small. While trade is least likely to be welfare-maximising in situations where quarantine restrictions are both expensive and relatively ineffective.

\section{Evaluating quarantine restrictions from a position of free trade}

The previous analysis of quarantine-restricted trade has been undertaken with respect to an initial closed economy

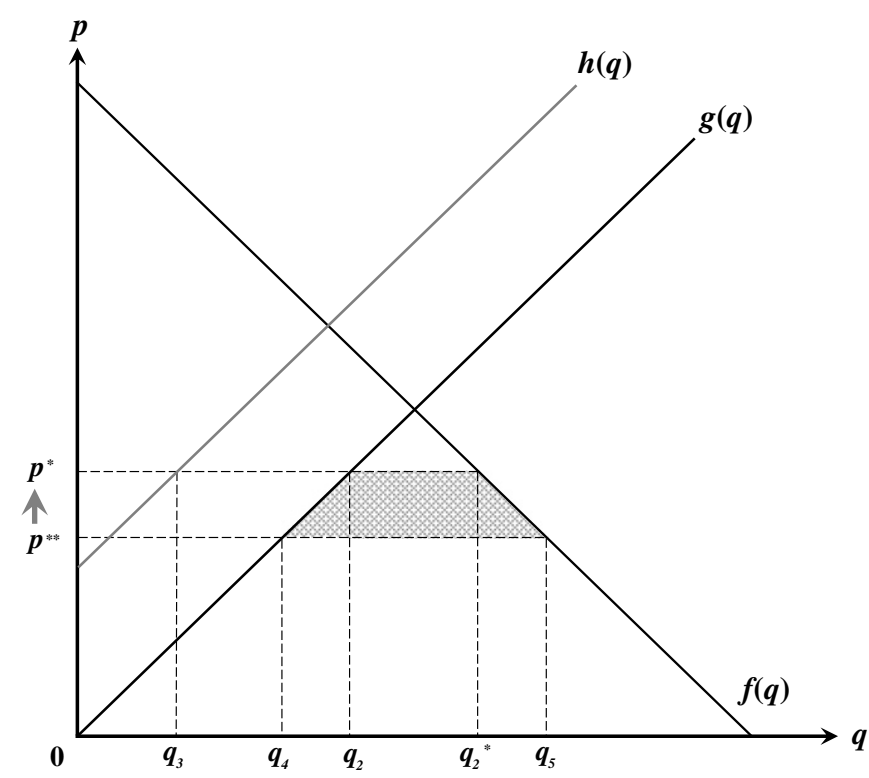

Fig. 2. The quarantine-restricted trade decision from a position of free trade.

position. However the reconciliation of the WTO Compliance with the Unilateral Welfare Maximisation decision rules can alternatively be undertaken with respect to an initial position of free trade. ${ }^{12}$

To see this, consider Fig. 2 where the domestic price is initially $p^{* *}$. In the absence of an outbreak the introduction of quarantine-restricted trade would see the domestic price increasing to $p^{*}$, resulting in a decrease in consumer surplus, but an increase in producer surplus. Moreover, it can be seen from Fig. 2 that the loss of consumer surplus more than outweighs the gain in producer surplus, resulting in the conventional loss of trade, LT. This is represented by the shaded region of Fig. 2 .

However, the new quarantine restrictions will also reduce the probability of an outbreak, from $r^{* *}$ (for free trade) to $r^{*}$, resulting in a reduction in the expected impact of the invasive species, and represented by

$\mathrm{EI}^{* *}=\mathrm{EI}_{\mathrm{F}}-\mathrm{EI}_{\mathrm{Q}}$

where $\mathrm{EI}_{\mathrm{F}}$ is expected impact in the position of free trade.

Following the approach of the Reconciliation section, if LT is used as the basis for setting the ALOP, then for both decision rules quarantine-restricted trade will be introduced if $\mathrm{EI}^{* *}>\mathrm{LT}$ and not introduced if $\mathrm{EI}^{* *}<\mathrm{LT}$.

On this basis, for both decision rules quarantine restrictions would be introduced from a position of free trade only if the gains in terms of a reduction in the expected costs of an outbreak exceeded the losses in terms of a net trade loss of consumer over producer surplus.

\footnotetext{
${ }^{12} \mathrm{We}$ are grateful to an anonymous reviewer for suggesting this to us.
} 


\section{Complexities}

\section{Bilateral net benefit maximisation}

If the welfare of trading partners were to be considered equally alongside that of the domestic economy another layer is added to the complexity of the decision to allow trade subject to quarantine measures. Consider the market for the traded good in the overseas country. The market clearing price is presumably below the price at which it supplies the Australian market. When trade takes place the domestic price rises, causing the quantity demanded by foreign consumers to fall. With demand now supplemented by Australian consumers, the total quantity of the good sold by foreign producers is greater.

Foreign consumer surplus $(\overline{\mathrm{CS}})$ is set to decline due to the price rise induced by re-directing a proportion of supply to the Australian market. But, this is more than offset by the rise in foreign producer surplus $(\overline{\mathrm{PS}})$. The traditional gains from trade for the foreign economy $(\overline{\mathrm{GT}})$ can therefore be stated as

$\overline{\mathrm{GT}}=\Delta \overline{\mathrm{PS}}-\Delta \overline{\mathrm{CS}}$

If these gains were to be considered by the importing country, in this case Australia, bilateral gains from trade $\left(G_{B}\right)$ can then be determined as

$\mathrm{GT}_{\mathrm{B}}=\mathrm{NG}_{\mathrm{E}}+\overline{\mathrm{GT}}$

As the importing country, the implication is that Australia would positively influence social welfare of the global economy by entering into quarantine-restricted trade as long as $\mathrm{GT}_{\mathrm{B}}>0$. Even where $\mathrm{NG}_{\mathrm{E}}<0$ there may still be sufficient gains to be made in a trading partner's economy to warrant the relaxation of import restrictions.

Of course, the political reality is that the populations with which Australia trades do not pay taxes in Australia or vote in Australian elections. But an objective economic analysis that includes the impact of trade policies on both economies may, at least to some extent, influence trade policy decisions, particularly when it is a developing nation making a market access request.

\section{The appropriate level of protection}

The politically sensitive nature of quarantine issues goes some way to explaining the lack of ALOP definition across trading regions, particularly where human health is concerned. Conventional neo-classical demand analysis for health care is often challenged by the view that health is such an important good that it cannot be traded off against other goods that society consumes. While it may not be the case that preferences for health are lexicographic, they are certainly high (Besley, 1989). To infer just how high society values such goods by way of an explicit policy statement concerning the ALOP is to court political disaster. In the same way that an acceptable number of human fatalities resulting from zoonotic disease outbreaks can never be specified, policies also avoid stating the acceptable number of species extinctions, or degree of habitat loss. Using the GT to bolster ALOP specification does not avoid these concerns, but merely provides a quantitative benchmark around which deliberation and debate can take place. The resulting decision on how to manage invasive species risks will rely on expert judgement.

As a consequence the use of GT benchmarking could reveal non-uniformity in the application of risk standards. Article 5.5 of the SPS Agreement prohibits the use of "arbitrary or unjustifiable distinctions" in the levels of risk deemed appropriate across different commodities (GATT, 1994). However, consistency can be viewed as a long-term goal for a biosecurity system, and to this end the approach developed in this paper could facilitate moves towards the consistency objective. It is inevitable that from time to time WTO Members will alter their ALOPs in response to new information or technological changes (Gascoine, 2001). With no precise definition of an ALOP, Article 5.5 permits a degree of flexibility in the application of standards, and an ALOP is not necessarily expected to be applied with absolute consistency. Any differences should be non-arbitrary and justifiable, but it is not clear under what circumstances inconsistent treatment would be deemed WTO-legal (Gascoine, 2001; Henson, 2001).

Perhaps more pressing than a lack of political will to express the ALOP using GT is the questionable reliability of producer and consumer surpluses as measures of social welfare. While the impacts of a particular species extending to multiple industries poses no particular methodological problems (beyond determining the expected supply curve shifts in each industry), non-market impacts are far more complex. The challenge associated with eliciting values for environmental flow-ons is well documented. The tremendous growth in the literature following the Exxon Valdez disaster has been unprecedented (Adamowicz, 2004). However, significant though this body of work is, it is often of little use when attempting to quantify invasive species impacts. There are several reasons why this is the case.

Firstly, environmental externalities often involve marginal changes in the population or health of an environmental resource, rather than its complete destruction. Eliciting values for these marginal changes is yet to be attempted. Secondly, the willingness of an economic agent to pay to protect an environmental good (or to guard against changes in its wellbeing) can not be explained without understanding the sociological elements involved in that agent's decision-making process. For instance, the income elasticities associated with environmental goods are thought to be large an positive, implying income has a significant influence on a person's willingness to pay to protect the environment (Whitby, 2000). Finally, non-use values for environmental amenities must be considered. While an agent might not receive tangible benefits from 
knowing these amenities to be in a favourable state of health, they may nonetheless be willing to pay to gain utility from merely knowing this to be the case. This is particularly important when a change induced by an invasive species is irreversible, or an affected ecosystem component is irreplaceable.

Other complexities that concern the use of gains from trade in practical policy-making include equity issues, distributional issues, regional issues and political issues. By effectively 'benchmarking' using consumer and producer surplus, the disproportional nature of policy impacts is not taken into consideration. Hence, it must be acknowledged that additional information is required in practice to form appropriate policies.

\section{Conclusion}

This paper has explored the use of economic analyses in trade and quarantine issues. Past examples in the literature have tended to follow high-profile market access requests, but have not produce a consistent approach to revealing the benefits and costs of trade. Compliance with the SPS Agreement requires that a country imposing import restriction on imported products be able to demonstrate that the risks of pest and disease contamination being prevented are legitimate using an internationally accepted standard, but one which only recognises production impacts of an outbreak as relevant economic factors. However, it has been argued that an alternative approach which considers both consumer and producer welfare as relevant policy criteria may lead to more socially desirable trade decisions.

The aim of this paper has been to show that these alternative trade decision frameworks can be reconciled such that they produce the same outcome regarding whether or not trade is permitted. It also highlighted the key role of two parameter values in influencing the decision regarding allowing quarantine-restricted trade:

(1) the costs associated with imposing quarantine restrictions on trade (which affect both the gains from trade and the expected impact of an outbreak), and;

(2) the differential risk of an outbreak associated with quarantine-restricted trade compared with no trade (which affects only the expected impact of an outbreak).

It follows that quarantine-restricted trade is most likely to be welfare-maximising in situations where both the costs of imposing quarantine restrictions and the differential risk of an outbreak associated with allowing quarantinerestricted trade are relatively low. While trade is least likely to be welfare-maximising in situations quarantine restrictions are both expensive and not very effective. In terms of net social welfare, it is important to consider these findings when deciding on appropriate invasive species risk management strategies.

\section{References}

Australian Pork Ltd v Director of Animal \& Plant Quarantine, 2005. FCA 671 (27 May 2005), Federal Court of Australia, Sydney.

Adamowicz, W.L., 2004. What's it worth? An examination of historical trends and future directions in environmental valuation. The Australian Journal of Agricultural and Resource Economics 48 (3), 419-443.

Besley, T., 1989. The Demand for Health Care and Health Insurance. Oxford Review of Economic Policy 5 (1), 21-33.

Bhati, U.N., Rees, C., 1996. Fireblight: a cost analysis of importing apples From New Zealand. A Report Prepared for the Australian Quarantine and Inspection Service, Australian Bureau of Agricultural and Resource Economics, Canberra.

Biosecurity Australia, 2002. Importation of fresh bananas from the Philippines: Draft IRA Report. B. Australia, Agriculture Fisheries and Forestry - Australia, 355pp.

Biosecurity Australia, 2004a. Generic IRA for Pig Meat. B. Australia, Agriculture Fisheries and Forestry, Australia.

Biosecurity Australia, 2004b. Importation of apples from New Zealand Revised Draft IRA Report. B. Australia, Department of Agriculture, Fisheries and Forestry. Part A, 533pp.

Biosecurity Australia, 2004c. Revised Draft IRA Report for Bananas from the Philippines. Fact Sheet Retrieved 20th November 2005. <www.affa.gov.au/content/output.cfm?ObjectID=9EBDCF3B-9F9F-4220A584106C8B0D6D02-105k>

Buckner, S., 1995. Reducing Fireblight. The Grower. October 8.

Cook, D.C., 2002. The Economics of Quarantine: A Consumer Perspective. School of Agricultural and Resource Economics. Ph.D. Thesis, Perth, The University of Western Australia, 170pp.

Cook, D.C., Fraser, R.W., 2002. Exploring the regional implications of interstate quarantine policies in Western Australia. Food Policy 27 (2), 143-157.

DPIE, 1988. Australian quarantine requirements for the future: Report of the Quarantine Review Committee. Department of Primary Industries and Energy, Canberra.

DPIE, 1990. The Australian Veterinary Emergency Plan. Canberra, EXANDIS.

Gascoine, D. 2001. The 'appropriate level of protection': an Australian perspective. In: Anderson, K., McRae, C., Wilson, D. (Eds.), The Economics of Quarantine and the SPS Agreement. Centre for International Economic Studies and the Department of Agriculture, Fisheries and Forestry, Australia/Biosecurity Australia, Adelaide, pp. 132-140.

GATT, 1994. Agreement on the application of sanitary and phytosanitary measures. In: The Results of the Uruguay Round of Multilateral Trade Negotiations: The Legal Texts (Ed.). General Agreement on Tariffs and Trade Secretariat, Geneva, pp. 69-84.

Hafi, A., Reynolds, R., Oliver, M. 1994. Economic Impact of Newcastle Disease on the Australian Poultry Industry, ABARE Research Report 94.7. A.B.o.A.a.R. Economics, Australian Government Publishing Service, Canberra.

Henson, S. 2001., The 'appropriate level of protection': a European perspective. In: Anderson, K., McRae, C., Wilson, D. (Eds.), The Economics of Quarantine and the SPS Agreement. Centre for International Economic Studies and the Department of Agriculture, Fisheries and Forestry - Australia/Biosecurity Australia, Adelaide, pp. 105-131.

Hinchy, M., Fisher, B., 1991. A Cost-Benefit Analysis of Quarantine. Australian Bureau of Agricultural and Resource Economics, Canberra.

Hinchy, M.D., Low, J., 1990. Cost-benefit analysis of quarantine regulations to prevent the introduction of fire blight into Australia, Report to the Australian Quarantine and Inspection Service, Australian Bureau of Agricultural and Resource Economics, Canberra.

James, S., Anderson, K., 1998. On the need for more economic assessment of quarantine policies. The Australian Journal of Agricultural and Resource Economics 42 (4), 425-444. 
Levine, J., D'Antonio, C., 2003. Forecasting biological invasions with increasing international trade. Conservation Biology 17 (1), 322326.

Lonsdale, M., Floyde, R., Vickers, R., Barro, P.D., Chakraborty, S., Groves, R., Clarke, G., 2001. Implications of Incursion Ecology for Managing Incursions in the Plant Sector. Canberra, CSIRO Entomology, Canberra.

McKelvie, L., 1991. The Economic Impact of Whirling Disease on the Australian Salmonid Industry. Australian Bureau of Agricultural and Resource Economics, Canberra.

McKelvie, L., Reid, C., Haque, M., 1994. Economic Impact of Salmonid Diseases: Furunculosis and Infectious Haematopoeitic Necrosis (IHN): Report to the Australian Quarantine and Inspection Service, Australian Bureau of Agricultural and Resource Economics, Canberra.

Nairn, M., Allen, P., Inglis, A., Tanner, C., 1996. Australian QuarantineA Shared Responsibility. Department of Primary Industries and Energy, Canberra.

Nunn, M.J., 2001. The analytical foundation of quarantine risk analysis. In: Anderson, K., McRae, C., Wilson, D. (Eds.), The Economics of Quarantine and the SPS Agreement. Centre for International Economic Studies and Agriculture, Fisheries and Forestry Australia/ Biosecurity Australia, Adelaide, pp. 29-52.

Olson, L., Roy, S., 2005. On prevention and control of an uncertain biological invasion. Review of Agricultural Economics 27 (3), 491-497.

Roberts, D., 1998. Implementation of the WTO agreement on the application of sanitary and phyto-sanitary measures: agriculture in the
WTO, Situation and Outlook Series, WRS-98-4. E.R. Service, US Department of Agriculture, Washington, DC.

Roberts, D., 2001. The integration of economics into SPS risk management policies: issues and challenges. In: Anderson, K., McRae, C., Wilson, D. (Eds.), The Economics of Quarantine and the SPS Agreement. Centre for International Economic Studies and the Department of Agriculture, Fisheries and Forestry, Australia/Biosecurity Australia, Adelaide, pp. 9-28.

Roberts, W. 1991. Consequences of Establishment of Fireblight in Australia, Information Paper No. IP/1/91. Bureau of Rural Resources, Canberra.

Snape, R. Orden, D. 2001. Integrating import risk and trade benefit analysis. In: Anderson, K., McRae, C., Wilson, D. (Eds.), The Economics of Quarantine and the SPS Agreement. Centre for International Economic Studies and the Department of Agriculture, Fisheries and Forestry, Australia/Biosecurity Australia, Adelaide, pp. 174-182.

Tanner, C., Nunn, M., 1998. Australian quarantine post the Nairn review. Australian Journal of Agricultural Economics 42 (4), 445-458.

Viljoen, J., McGillivray, M., Orton, T., Oliver, G., 1997. The Potential Impact of Fire Blight on the Australian Apple and Pear Industry: A Socio-Economic Study, Corporate Strategy Consulting, Camberwell.

Whitby, M., 2000. Challenges and options for the UK agri-environment: presidential address. Journal of Agricultural Economics 51 (3), 317-332.

WTO, 2000. Australia - Measures Affecting Importation Of Salmon, Recourse to Article 21.5 By Canada, Report of the Panel. Geneva, World Trade Organisation, 167pp. 